I Universidade Federal do Rio de Janeiro (UFRJ),

Programa de Pós-Graduação em Sociologia e Antropologia,

Rio de Janeiro, RJ, Brasil

josericardoramalho@gmail.com

"I Universidade Federal do Rio de Janeiro (UFRJ),

Programa de Pós-Graduação em Sociologia e Antropologia,

Rio de Janeiro, RJ, Brasil

José Ricardo Ramalho'

santosrodrigosp@gmail.com

\title{
HUW BEYNON: MARXISMO E SOCIOLOGIA
}

Esta entrevista com o sociólogo britânico Huw Beynon expõe aos leitores brasileiros uma trajetória que sugere forte ligação entre os escritos de Marx, uma militância política de compromisso com as causas dos trabalhadores, e a elaboração teórica de uma história que reconhece o papel decisivo de quem vive do trabalho. Seu livro Working for Ford tornou-se obra de referência no âmbito dos estudos do trabalho desde sua primeira edição no Reino Unido, em I973, tendo suscitado acalorados debates sobre as relações entre engajamento político e produção de conhecimento e sobre o formato narrativo do trabalho sociológico. No Brasil, o entrevistado manteve uma importante e duradoura conexão acadêmica, ${ }^{\mathrm{I}}$ teve livro, artigos e capítulos publicados em português e sua interlocução com pesquisadores de várias universidades imprimiu uma marca aos estudos sobre trabalho em nosso país.

Huw Beynon nasceu em Ebbw Vale, no País de Gales, cidade profundamente marcada pela mineração de carvão e pela siderurgia. Formou-se em Ciências Sociais pela Universidade de Liverpool (Reino Unido) e concluiu seu doutorado, em I999, pela Universidade de Manchester (Reino Unido). Sua trajetória profissional se confunde com a própria institucionalização da sociologia britânica. Em I968, tornou-se professor do recém-criado departamento de sociologia da Universidade de Bristol (Reino Unido) e em I 976 ingressou na Universidade de Durham - localizada em um antigo centro minerador de carvão. Em I987, assumiu uma cátedra na Universidade de Manchester e, em I999, 
tornou-se Diretor da School of Social Sciences da Universidade de Cardiff (Reino Unido). Desde 2008 tem se dedicado ao Welsh Institute for Social and Economic Research Data and Methods (WISERD), tendo sido seu primeiro Diretor (2008-20I0). Huw Beynon escreveu ou editou 20 livros, inúmeros artigos em periódicos, capítulos de livros e orientou extensamente na pós-graduação. Professor emérito da Universidade de Cardiff, recebeu vários prêmios e homenagens ao longo de sua carreira, dentre os quais os títulos de membro honorário do National Union of Mineworkers e da Academy for the Social Sciences.

Ao longo de suas várias viagens ao Brasil nos anos I990 e 2000, o entusiasmo e a emoção que Huw Beynon imprimia ao descrever suas análises acerca dos processos de mudança nas vidas dos trabalhadores nos setores automobilístico, bélico, siderúrgico e na mineração de carvão - dentre muitos outros - cativaram audiências inteiras de cientistas sociais. A "abertura da caixa preta" da pesquisa, proporcionada por suas obras e palestras, revelava maneiras sui generis de observação e engajamento com os trabalhadores de chão de fábrica e seus mundos sociais, em conversas nas mesas e bancos da cantina, nas filas para o almoço, para o ônibus e mesmo para a entrada e a saída das fábricas e minas - o que não poderia deixar de inspirar novos pesquisadores do trabalho.

A descrição em primeira mão dos dramas e dilemas cotidianos dos trabalhadores em uma disputa secular em torno do controle do processo de trabalho, no caso da pesquisa sobre os trabalhadores da Ford, e acerca de sua própria reprodução social como trabalhadores fabris, municiava de argumentos e legitimava a opção de um conjunto de pesquisadores brasileiros que vinham se dedicando a valorizar o papel dos trabalhadores na história política do país e a defender uma Sociologia do Trabalho que assumia como centrais as perspectivas daqueles que ganhavam a vida trabalhando em fábricas e cidades.

As críticas ao livro Working for Ford e aos modos de fazer pesquisa que surgiram a partir do establishment da sociologia britânica não surtiram efeito no Brasil. As observações sobre "falta de objetividade", por exemplo, foram vistas como fruto da sagacidade em perceber as revelações novas e surpreendentes sobre a vida no chão de fábrica, os dilemas políticos, pessoais, familiares e geracionais dos operários da Ford. O estilo de Huw Beynon reforçou a identificação dos pesquisadores brasileiros com a abordagem que aproximava o investigador de seu objeto de investigação.

No Brasil, a versão traduzida e publicada pela editora Paz e Terra, Trabalhando para a Ford, de I995, se integrou a uma corrente de estudos nas Ciências Sociais que assumia uma perspectiva similar, incorporando a dimensão da experiência dos trabalhadores e das culturas operárias como núcleo de discussões acerca das experiências brasileiras de mudança social e desenvolvimento industrial, assim como da conformação conflituosa das condições e relações de trabalho "modernas" no país. A tradução deste livro expressava, de 
antemão, "afinidades eletivas" insuspeitas entre os processos de institucionalização e desenvolvimento da Sociologia do Trabalho no Brasil e no Reino Unido, além de apontar alguns dos caminhos de estreitamento de preocupações comuns.

Em um registro precoce, no Reino Unido, a ascensão dos conservadores e de Margareth Thatcher (I979) e a eclosão dos conflitos em torno do encerramento das operações de unidades fabris, como a da Massey Ferguson (I978) e a da British Leyland Motor Co. (I98I), constituíram as primeiras vagas de uma mudança dramática no cenário das relações de trabalho no mundo. O engajamento acadêmico e político de Huw Beynon assumia contornos ainda mais importantes, e o autor - assim como vários de seus colegas britânicos - se envolveu na análise e nas disputas em torno do chamado "movimento de fechamento" de fábricas. Panfletos, relatórios e obras acadêmicas acerca da inadaptação das formas de organização e estratégias sindicais em face da conformação de estruturas corporativas em rede geograficamente dispersas de empresas multinacionais passaram a compor o núcleo de suas atividades.

Em fins dos anos i980 e início da década de I990, a Sociologia do Trabalho brasileira passaria a lidar com os efeitos tardios da constituição destes sistemas transnacionais de produção e suas dimensões organizacionais e tecnológicas. A reestruturação produtiva varria elos inteiros de cadeias produtivas de bens e/ou serviços e se fazia acompanhar de processos políticos de redução de controles sobre capitais estrangeiros, privatização de setores estatais (como telecomunicações, siderurgia etc.) e disputas interestaduais pela atração de investimentos produtivos. Em especial, novos implantes industriais - automobilísticos, predominantemente - configuravam um "movimento de fuga" do eixo industrial de São Paulo e de seu ativismo sindical, recorrendo a estratégias locacionais de tipo greenfield, rememorando dramaticamente processos ocorridos no Reino Unido.

Mais importante, trabalhadores e sindicatos se defrontavam com novos dilemas, impulsionados por transformações organizacionais e tecnológicas corporativas, e diretamente relacionados à representação de contingentes e demandas cada vez mais plurais, passando por características demográficas, formas de contratação, padrões regionais de uso e remuneração do trabalho etc. A crítica de Beynon às interpretações então correntes acerca da natureza fragmentada do trabalho - a noção de trabalhador hifenizado se tornou célebre - incorporava esses desafios e permanecia ativa na sustentação de uma abordagem acerca das mudanças nas estruturas sociais dos países capitalistas centrada na classe.

Desde os anos 2000, os trabalhos de Beynon vêm enfocando as dinâmicas políticas estruturantes da conformação do mundo do trabalho e das vidas dos trabalhadores no Reino Unido. É digna de nota sua compreensão dos múltiplos e contraditórios papéis desempenhados pelo Partido Trabalhista, em sua 
relação mutuamente constitutiva com o movimento sindical britânico, e da renovada esperança - em especial entre a juventude - na capacidade de lideranças emergentes articularem uma nova resposta política ao arranjo societário britânico, uma resposta que se oponha decisivamente aos programas hegemônicos de austeridade e bélicos das últimas três décadas.

As reflexões de Beynon proporcionam ferramentas heurísticas potencialmente úteis para a compreensão do cenário político e econômico brasileiro. Após cerca de uma década de crescimento econômico, redução da pobreza e incremento das condições e relações de trabalho no Brasil, novas respostas políticas são urgentes na reconfiguração do arranjo social de grupos e classes em conflito que marca a sociedade brasileira. Os modos de organização e es tratégias sindicais e partidárias trabalhistas continuam sendo centrais nesse processo, demandando a emergência de novas formas de liderança e representação, assim como um projeto democrático e mais includente, social, econômica e politicamente. A obra de Beynon é, portanto, atual e incontornável na tarefa de compreensão de projetos de transformação dos trabalhadores e de seus papéis na estruturação da vida social, no Brasil e no mundo.

José Ricardo Ramalho e Rodrigo Santos. Professor Beynon, qual a influência de Marx e do marxismo em sua trajetória como cientista social?

Huw Beynon. Fui criado em uma cidade chamada Ebbw Vale, no Sul do País de Gales; uma cidade dominada por uma siderúrgica enorme e três minas de carvão. A classe trabalhadora tinha completa hegemonia na cidade. O MP (Member of Parliament) local era Aneurin Bevan, líder da ala esquerda do Partido Trabalhista (Labour Party). ${ }^{2}$ Meus avós paterno e materno eram mineiros, meu pai era professor. Ele voltou da Guerra com a expectativa de que haveria uma mudança revolucionária. Por muitos anos foi secretário do Partido Trabalhista Independente (Independent Labour Party), de esquerda, que se tornou muito crítico ao Governo Trabalhista. Ele vocalizou as críticas que Ralph Miliband iria desenvolver, posteriormente, em seu livro Parliamentary socialism. Tendo isso como pano de fundo em minha vida, estava aberto às ideias de Karl Marx, que para mim ofereciam uma crítica ao capitalismo do ponto de vista da classe trabalhadora.

Entretanto, nos anos de I950, a sociologia mal existia como disciplina acadêmica na Grã-Bretanha. Havia três departamentos, alguns departamentos de antropologia, mas de um modo geral a ciência social era representada pela economia, que foi a minha primeira graduação. Interessado em sociologia industrial, engajei-me como estudante de graduação no Departamento de Ciências Sociais da Universidade de Liverpool, que no começo dos anos I960 era o principal centro britânico de pesquisa social e o primeiro a desenvolver um programa de pesquisa empírica sobre relações de trabalho e relações de vizinhança na Grã-Bretanha. Ali o que predominava era uma abordagem positivis- 
ta, ligada a ideias de reforma social e cooperação entre a gerência e os sindicatos. Isso refletia a situação geral da sociologia britânica que adotava uma abordagem funcionalista, sem considerar seriamente o marxismo como uma tradição teórica viável.

Fora das universidades, contudo, o marxismo existia dentro do Partido Comunista por meio de vários agrupamentos trotskistas, e das atividades de indivíduos particularmente talentosos como Eric Hobsbawm, Raymond Williams e Edward Thompson, tendo todos eles sido primeiramente tutores de educação de adultos nos departamentos de extensão das universidades. O grupo que produziu a New Left Review incluía Thompson e Stuart Hall, entre outros, e ela se tornou uma fonte importante de informação e debate. Foi na New Left Review que eu li "O Marx desconhecido" ("The unknown Marx", 48, I968, p. 4I6I), de Martin Nicolaus, texto que apresentou os primeiros escritos sobre alienação para os leitores ingleses, e que embasaram minhas interpretações sobre o modo como os homens com quem conversei na minha pesquisa sobre a Ford falavam de seu trabalho e de suas vidas. Observei que o tema da alienação tinha sido trabalhado por Alvin Gouldner em seu livro The coming crisis of Western sociology. Naquele momento, Gouldner passava de marxista a weberiano radical. Mesmo assim achei o texto instigante. Ele escreveu sobre o modo como seres humanos criam a sociedade com regras e instituições e, por sua vez, são controlados por elas. Qualificou esse processo como alienação e sustentou que havia uma tendência da sociologia profissionalizada em descrever esse arranjo, mais do que propriamente desafiá-lo e mudá-lo. Isso me surpreendeu por ser semelhante à crítica da filosofia de Marx e reforçou teoricamente a minha impressão de que a sociologia precisava ser uma disciplina crítica.

Naquela época estava trabalhando como professor no novo departamento de sociologia da Universidade de Bristol e, enquanto estive lá, também dei aulas noturnas para trabalhadores pelo Departamento de Extensão. Percebi que havia grande interesse dos trabalhadores pelo marxismo e acabei ensinando alguns dos seus princípios, utilizando escritos de Marx disponíveis em forma de panfleto. Lembro-me de discutir "Trabalho assalariado e capital" e "Salário, preço e lucro" com trabalhadores da construção! Foi uma experiência que, à época, confirmou minhas expectativas com relação ao marxismo. Ao mesmo tempo muitos de nós estávamos envolvidos em algum "Grupo de leitura do Capital", o que, somado às traduções dos escritos de Althusser, fazia parecer que todo o eixo de discussão havia mudado e o marxismo se tornado central; assim ele permaneceu para mim.

J.R.R. e R.S. Qual foi a influência de Marx e da intelectualidade marxista na sociologia britânica (do trabalho)?

H.B. Durante os anos I960, a sociologia passou rapidamente a se estabelecer em departamentos fortes e com grande número de estudantes de nível supe- 
rior. Expandiu-se no contexto de um movimento trabalhista bastante organizado que contava com sindicatos com quinze milhões de filiados, um Partido Trabalhista com meio milhão de membros, um Partido Comunista influente e uma variedade de agrupamentos de trotskistas e de sindicalistas atuantes em comunidades e nas organizações de trabalhadores, especialmente nos campi, em campanhas e manifestações. Em I968, os eventos em Paris colocaram universidades e estudantes no centro do dissenso e da inquietude política. Todos esses elementos estavam presentes nos departamentos de sociologia. Pressões pela profissionalização da nova disciplina apareceram concomitantemente com demandas que insistiam em seu papel público e na necessidade de seu engajamento nas questões levantadas pelo movimento trabalhista. A discussão do marxismo já era uma realidade, de modo que quando o livro Trabalho e capital monopolista: a degradação do trabalho no século XX, de Harry Braverman, foi publicado em I974, a resposta foi imediata e positiva. Tratava-se de uma crítica explicitamente marxista às práticas gerenciais tayloristas, que associada aos eventos "das ruas", produziu um intenso engajamento com a teoria da mudança do trabalho e do emprego e com as experiências diretas dos trabalhadores. Muito disso foi divulgado nas páginas de uma nova revista - Capital \& Class. Lançada em I977, a partir da "Conferência dos Economistas Socialistas", a revista era, lembro-me, comprometida em "desenvolver uma crítica materialista do capitalismo na tradição marxista". Na tentativa de ultrapassar fronteiras disciplinares, o periódico oferecia espaço para artigos de ciências sociais que detalhavam pesquisas empíricas e articulações com o movimento trabalhista. Reler essas páginas traz à lembrança assuntos relacionados à "crise britânica" que se desenrolava então. A ênfase na análise do processo de trabalho foi instrutiva e levou ao engajamento de contadores e teóricos do gerenciamento nas Escolas de Administração. Estabeleceu-se também, a cada ano, uma Conferência Internacional sobre Processo de Trabalho (International Labour Process Conference), apoiando e incentivando pesquisa sobre processo de trabalho em diferentes locais de trabalho ao redor do mundo.

Esse movimento passou a ocorrer nas ciências sociais, mas no que diz respeito aos departamentos de sociologia, a participação fundamental da Universidade de Warwick foi uma exceção. Cada vez mais o estudo e o ensino sobre o local de trabalho se concentrou nas Escolas de Administração das universidades. A essas mudanças institucionais nas universidades se seguiram mudanças dramáticas nas condições gerais de trabalho e de emprego. A crise britânica que se aprofundava e a "globalização" que emergia no horizonte, junto com o fechamento de locais de trabalho e a reação sindical, acabaram por exercer um impacto significativo sobre o modo como os sociólogos passaram a teorizar sobre trabalho, emprego e organização sindical. Braverman, por si só, não era mais suficiente. Teorias da desqualificação não estavam ajudando a entender muitas dessas questões críticas enfrentadas pelo movimento tra- 
balhista, ou a entender como os interesses de um grupo de trabalhadores podia ser medido em relação a outros. Isto demandou a reincorporação da dimensão espacial, e a colaboração dos geógrafos se tornou lugar comum.

J.R.R. e R.S. Sua pesquisa na Ford Motor Co. em Liverpool, no final dos anos de I960, valorizando o ponto de vista dos trabalhadores, pode ser considerada um exemplo de abordagem marxista da realidade social?

H.B. Espero que sim. Para Marx, o local de trabalho é o lugar da exploração - é onde a mais-valia é extraída através do processo de produção. Para o trabalhador, a realidade é aquela em que ele/a precisa trabalhar para obter um salário para viver. Trabalhadores da linha de montagem festejavam quando a linha parava. Ou quebrava. Eles preferiam ficar do lado de fora jogando futebol. Escrevi sobre isso como expressões da alienação descrita por Marx e evocada por Sartre, quando tratou o trabalho moderno como uma "vigilância sem conteúdo". Também me encorajou a desenvolver a ideia do operário-massa e a linha de montagem que nunca para, como o tema central do meu livro. Meu estilo de escrita foi influenciado por isto. Em vez de avaliar à distância uma determinada citação ou atividade, partia da construção das frases dos trabalhadores ao falarem sobre suas experiências, frustrações e emoções. Marx, como se sabe, escreveu sobre como as pessoas fazem sua própria história, mas não nas condições de seu próprio arbítrio, reunindo agência e estrutura. Muitas vezes, a "agência" é esquecida. Por isso, um dos temas centrais do meu livro Trabalhando para a Ford: trabalhadores e sindicalistas na indústria automobilística se refere ao modo pelo qual trabalhadores e delegados sindicais lutavam para mudar e melhorar o local de trabalho. Em I969, quando entraram em greve, muitos deles sentiram que estavam "fazendo história".

J.R.R. e R.S. Trabalhando para a Ford significou uma reviravolta em termos da prática de pesquisa junto à classe trabalhadora britânica. Quais contribuições do livro você destacaria como novos tópicos e abordagens de pesquisa para a sociologia britânica?

H.B. Me convenci de que a sociologia, para desempenhar o papel esclarecedor que preconizávamos em nossas aulas, deveria ser crítica e reunir o engajamento e o artesanato intelectual ressaltados por Wright Mills, em seu A imaginação sociológica. "Sociologia para sociólogos", escrevi, era um absurdo. Tinha achado na formulação de Sartre sobre serialidade e "grupos em fusão", um modo de pensar sobre como os trabalhadores poderiam quebrar o isolamento e o anonimato da produção em massa. Também passei a ver a sociologia como um modo de destravar o egoísmo e o distanciamento do intelectual/escritor. Minha preocupação era que o livro fosse lido para além da academia, e por isso deveria ser escrito de um modo que atraísse novos leitores. No Prefácio da $2^{\mathrm{a}}$ edição de Trabalhando para a Ford faço um relato dos diferentes modos pelos 
quais o livro foi lido, enfatizando especialmente as cartas que havia recebido de operários. Os trabalhadores descreviam suas vidas sempre atadas às fábricas e como, em toda parte, não conseguiam fugir do sentimento de que eram menos importantes do que as máquinas.

Em Por uma sociologia pública, Burawoy classificou o meu trabalho como uma "sociologia pública de baixo para cima" (contraste que ele fez com o trabalho de Giddens - "de cima para baixo"). O debate que Burawoy desencadeou em 2004 se adequa bem ao modo como tentei trabalhar. Também discuti essas questões com pesquisadores e estudantes no Brasil. Na África do Sul provocaram debate e promoveram o apelo de Eddie Webster ${ }^{3}$ para que os pesquisadores "voltassem ao chão de fábrica" e "escutassem as vozes dos trabalhadores".

Penso que a ideia de uma luta pelo controle no local de trabalho e o modo como esse controle opera, além de como o sindicalismo pode interferir, são temas específicos importantes. A linha de montagem era uma realidade, além de uma metáfora útil. O telefone toca para trabalhadores de call centers e um novo chamado precisa ser atendido. Na Grã-Bretanha, os sociólogos criaram o termo "linha de montagem na cabeça" para explicar esse novo tipo de controle sobre o trabalho.

J.R.R. e R.S. De que modo a abordagem marxista de E. P. Thompson sobre a classe trabalhadora tem sido um modelo para os sociólogos britânicos? As perspectivas cultural e de longo prazo permanecem?

H.B. Thompson era muito crítico das abordagens sociológicas (por vezes de modo desdenhoso), especialmente nos estudos sobre classes sociais. Diria que os sociólogos gostam de "parar a máquina do tempo", o que para ele fornecia a chave para a dinâmica de classe, por ser uma relação social que se desenvolvia ao longo do tempo. Seu trabalho permaneceu importante, particularmente para a história do trabalho. A "virada cultural" no marxismo veio dos escritos de Stuart Hall e seus colegas e do modo como interpretaram o thatcherismo e produziram uma literatura sobre o pós-fordismo através do retorno aos escritos de Antonio Gramsci. Isto foi acompanhado por uma mudança política, quando o Partido Comunista Britânico adotou o "eurocomunismo" de modo controverso, através de sua nova revista, Marxism Today.

J.R.R. e R.S. Qual a relação entre as mudanças nos movimentos sindical e trabalhista e o desenvolvimento da sociologia na Grã-Bretanha desde a Guerra?

H.B. Essa é uma grande questão porque as coisas mudaram tanto e de muitas maneiras diferentes. Escrevi sobre isso no Global Labor Research e apresentei argumentos para refletir sobre como os sindicatos, no período pós-guerra, desempenharam papel central na sociedade britânica. A adesão sindical tinha chegado a $70 \%$ da força de trabalho no final dos anos de I970, justo quando (incidentalmente) foi registrado o maior nível de felicidade de todos os tempos para os britânicos! 
Contudo, isso durou pouco, pois em I976 a Grã-Bretanha enfrentou uma crise de desvalorização cambial que envolveu de modo controverso o apoio do FMI; um apoio que veio com as amarras punitivas que obrigaram o governo trabalhista de James Callaghan a cortar gastos públicos em $£ 8$ bilhões entre I977 e I979. Isso pavimentou o caminho da vitória dos Conservadores, em I979, sob a liderança da Sra. Thatcher e implicou mudanças jamais experimentadas pela estrutura da indústria britânica.

Entre I979 e I982, o emprego na indústria foi reduzido a quase a metade. Três milhões de postos de trabalho foram perdidos devido ao fechamento de fábricas. Como consequência, e em contraste às greves agressivas do período anterior, trabalhadores e dirigentes sindicais passaram a preocupar-se com táticas defensivas de modo a resistir ao "movimento de fechamento". Alguns trabalhadores ocuparam suas fábricas e envolveram-se em campanhas mais amplas alertando para as consequências públicas do fechamento das empresas privadas. O "movimento de fechamento" foi implacável, e muitos sociólogos engajaram-se de diferentes maneiras no apoio às tentativas de resistência dos trabalhadores. Em Kilmarnock, por exemplo, um grupo da Universidade de Strathclyde passou a trabalhar com o comitê dos delegados sindicais da Massey Ferguson de Glasgow, em I977.

Merseyside foi uma das áreas particularmente atingidas, e o fechamento da fábrica de automóveis British Leyland, em Speke, em I98I, se tornou emblemático da mudança que estava acontecendo no e para o movimento trabalhista. Após o que foi considerada uma série de ações de provocação dos gerentes locais, um comitê de empresa bem organizado articulou uma forte greve de resposta. Na primeira semana da greve, a empresa anunciou que a fábrica iria fechar, imobilizando os grevistas, que ficaram desempregados. Esses trabalhadores constituíram um grupo dentro do sindicato denominado "trabalhadores desempregados" e me convidaram para escrever sobre What happened at Speke. Foi publicado como um panfleto pelo grupo. Depois, uma versão condensada saiu na New Society. A ênfase do texto estava nos tempos de mudança e na necessidade de modificar estratégias - não desocupem o local sem pensar!

O Nordeste da Inglaterra foi outra das velhas regiões industriais afetada pelo fechamento de fábricas. Naquela época estava trabalhando na Universidade de Durham e, junto com um de meus colegas, fiz contato com o maior sindicato da região, o General and Municipal Workers Union, para escrever um relatório sobre a organização sindical nas fábricas de corporações multinacionais daquela região. Esse relatório (Global outpost) foi amplamente distribuído e quase atingiu as proporções de Samizdat 4 quando cópias adicionais foram encomendadas. Nas discussões com os trabalhadores nas bases sindicais, esse relatório serviu para mostrar como a tomada de decisão das empresas não mais acontecia em nível regional, mas ocorria nas sedes localizadas ao redor 
do planeta. Além disso, os trabalhadores das corporações deixavam de ver-se como parte da classe trabalhadora do Norte da Inglaterra, para ver-se como empregados de uma hierarquia corporativa transnacional. Tal situação levou a discussões sobre o tipo apropriado de organização sindical para responder a esse desafio e a resposta que ela pode dar. Um bom exemplo foi o comitê de comissões de fábrica organizado na Companhia Vickers, um dos principais produtores britânicos de armas, quando os trabalhadores desafiaram a corporação com a proposta de "planos alternativos". A noção de tais planos alternativos também foi desenvolvida na Plessey Co., então uma companhia britânica dos setores de defesa, eletroeletrônico e de telecomunicações, e levada à discussão no Instituto para o Controle Operário (Institute for Workers Control) - dirigido à época por Ken Coates ${ }^{5}$ e que também contava com uma unidade para sociólogos que buscavam uma conexão com o movimento trabalhista. Embora estas iniciativas em torno dos usos da tecnologia e da capacidade humana não tenham sido perdidas e tenham um impacto contínuo, por outro lado elas não foram suficientemente efetivas para evitar o fechamento das fábricas. Mesmo após uma longa campanha de apoio à Vickers Scotswood, no oeste de Newcastle, a fábrica foi fechada.

J.R.R. e R.S. Você dedicou uma boa parte da sua pesquisa aos mineiros de carvão e sua organização como uma espécie de ator coletivo paradigmático. No Brasil, a sociologia do trabalho também atribuiu um papel especial aos metalúrgicos. Como o uso da teoria marxista e sua ênfase na produção se relaciona com esse tipo de análise?

H.B. Essa é uma questão interessante. Para começar, é útil mencionar que os mineiros de carvão não eram muito considerados pela análise de Marx sobre o crescimento da indústria e do proletariado. Os mineiros também estão ausentes na descrição de Edward Thompson em A formação da classe trabalhadora inglesa. É uma omissão interessante se pensarmos o tamanho da força de trabalho mineira e a importância do carvão para o desenvolvimento da "revolução industrial" baseada nas máquinas a vapor. Isto reflete a atenção dedicada ao crescimento do sistema de produção fabril que (em contraste com a mineração) representou um ponto de partida revolucionário.

Meu trabalho anterior e meus quatro primeiros livros basearam-se em estudos de trabalhadores de diferentes indústrias: alimentícia, montagem de carros, química e de construção civil. Em Trabalhando para a Ford, termino com uma consideração dos operários da indústria automobilística sobre outros grupos de trabalhadores, especialmente os mineiros que, como argumentei, surgiram com a demanda histórica das "minas para os mineiros". Sugeri que a ausência de tal demanda pelos operários metalúrgicos refletia sua experiência de trabalho alienado e a ausência de qualquer ligação entre a realidade cotidiana do trabalho na linha de montagem e um futuro utópico. No entanto, eles 
foram capazes de ação coletiva e nos anos de ig6o e I970 tornaram-se emblemas de novos modos de engajamento na luta de classes no local de trabalho. Desse modo, para o Estado, que considerava mudanças nas leis relacionadas aos sindicatos e às greves, os metalúrgicos passaram a ser a encarnação do "ator coletivo" que precisava ser controlado.

Os mineiros formaram um grupo diferente dentro da classe trabalhadora porque historicamente tinham conduzido suas lutas industriais com o objetivo de mudar as leis que regulavam a indústria da mineração - algo que derivava em parte dos perigos extremos associados à mineração e à privação social associada ao isolamento geográfico desta atividade. Esse isolamento trazia consigo densidade ocupacional, o que significava que, sob o sufrágio universal, os mineiros podiam determinar os resultados das eleições políticas. Como resultado, os mineiros (ou ao menos seu sindicato) formaram o coração do Partido Trabalhista. A nacionalização das minas derivou de uma demanda sindical e em consequência, no período pós-guerra, mineiros de carvão passaram a ser empregados do setor estatal da economia. O sistema de emprego estatal produziu benefícios e também submeteu o mineiro ao gerenciamento direto do Estado, o que foi objeto de disputa teórica no marxismo: a nacionalização era vista como meio caminho em direção ao socialismo; mas, por outro lado, ela podia ser vista como uma forma de corporativismo, subsidiando os custos energéticos para o capital privado. À medida que o tempo passou, esta última visão prevaleceu. Em I947, com a nacionalização das minas britânicas, havia 750 mil mineiros em um único sindicato. Nos anos de I960, a força de trabalho mineira foi cortada à metade, com mais de metade das minas fechadas sem uma única greve em protesto. Desse modo, e no contexto modificado dos anos de I980 (com o fechamento ou comprometimento dos principais centros de força política ocupados pelos metalúrgicos), a reação do sindicato dos mineiros à ameaça em larga escala de fechamento das minas tornou-se de grande interesse e importância. Ao entrar em greve no final do inverno e sustentá-la por um ano, eles mostraram uma resiliência fenomenal e uma grande capacidade de solidariedade local. Entretanto, eu não os consideraria como o "ator coletivo paradigmático", mas como uma forma particular de ação coletiva que emergiu do caráter de sua experiência industrial. Se de um lado Marx foi cuidadoso ao analisar a estrutura de uma economia capitalista e reconhecer a importância de diferentes departamentos, de outro, ele não suscitou a questão das diferentes experiências de classe através dessas estruturas. Isso é, de certo modo, assinalado por Michael Burawoy, em sua referência à necessidade de um marxismo sociológico.

J.R.R. e R.S. A despeito dos ataques políticos contra os mineiros e o fim da mineração de carvão, a Festa dos Mineiros de Durham (Durham Miners Gala) permanece um sinal da identidade de classe trabalhadora na Grã-Bretanha. Como você vê o significado deste evento? 
H.B. Vocês dois presenciaram esse evento em Durham e conhecem sua história - remonta a I87I, quando a Associação de Mineiros de Durham (Durham Miners Association) finalmente foi fundada após muitas tentativas fracassadas. A ideia do Gala - ou "o Grande Encontro" conforme muitos ainda o chamam era reunir anualmente todos os mineiros e suas famílias de todas as minas de carvão para uma ocasião social quando velhos amigos e seus familiares podiam se encontrar. Era também um evento político e se tornou um dos principais eventos do Partido Trabalhista, com a presença de suas principais lideranças entre os oradores convidados. As filiais locais do sindicato de mineiros são chamadas "lodge", e em Durham cada um tinha um estandarte; no Dia do Gala, eles desfilavam pelas ruas estreitas da antiga cidade acompanhados por uma banda musical e seguidos por homens, mulheres e crianças. Com o fechamento das últimas minas em I99I, muitos supuseram que a festa também iria acabar. No entanto, uma nova liderança do sindicato resolveu lutar pelo Gala, como uma lembrança dramática do que havia sido perdido, mas também como uma plataforma para o debate político. É impressionante que o Gala seja hoje um evento maior do que quando as jazidas foram abertas. Há muitas razões para isso.

Localmente, é evidente que a festa e seu cortejo reteve o interesse no passado, na mineração e nas lutas dos trabalhadores. Nos vilarejos onde as minas haviam fechado, talvez gerações antes, cresceu o interesse nos velhos estandartes. Tudo isso foi, ironicamente, financiado pelo Estado. Nessas áreas desprovidas, assistentes sociais e jovens trabalhadores fizeram dos estandartes um foco para as pessoas: recebiam apoio financeiro através do Fundo da Loteria Nacional, o que lhes permitia idealizar e produzir novos estandartes ou elaborar réplicas dos antigos. Ativistas sindicais aposentados foram ressuscitados nesse processo, adicionando uma nota de desafio à retomada dos estandartes. Assim mais estandartes locais se juntaram ao desfile no Gala e isso se tornou um processo cumulativo.

Ao lado disso, líderes de outros sindicatos que frequentaram o Gala como oradores quiseram se envolver nessa nova abertura e trazer seus próprios estandartes e delegações. Ironicamente, esse novo e importante desdobramento não teria sido possível quando as minas ainda estavam abertas e o Gala era visto como a preservação das pessoas cujas vidas dependiam do trabalho na indústria mineral. Com o fechamento das minas, o Gala e o "Grande Encontro" tornaram-se um evento sindical verdadeiramente nacional.

Ao comentarem a capacidade dos mineiros de carvão de organizar um evento desse porte e de atrair outros trabalhadores, as pessoas o associam ao impacto da greve de I984, quando os mineiros pararam por um ano numa tentativa de impedir o fechamento das minas. Seu legado histórico foi o Gala (frequentemente utilizam a palavra "herança"), e sua posição em I984 deu-lhes legitimidade. 
Em sua discussão da classe social, Marx escreveu sobre a importância das organizações nacionais e sobre o senso de comunidade. Sem comunidade não há classe. Eventos culturais e imateriais como o Gala podem ser vistos tanto como uma expressão de classe quanto como um dos ingredientes necessários para a sua sobrevivência.

J.R.R. e R.S. Você sustenta que a composição modificada da força de trabalho, sintetizada na ideia do "trabalhador hifenizado", mas também envolvendo conexões cruciais com gênero, etnicidade e populações marginalizadas e dependentes do Estado, é um grande desafio para a pesquisa. Como o movimento trabalhista e a sociologia têm tratado disso?

H.B. Em grande medida, acredito que a sociologia tem tratado dessas questões através de noções relacionadas à fragmentação. Tornou-se comum falar de uma classe trabalhadora fragmentada, o que se reflete no investimento de estudos separados desses fragmentos. De muitas maneiras, isso significa cair na armadilha contra a qual Gouldner nos alertou.

J.R.R. e R.S. Entender o "trabalhismo" como um "tipo particular de resposta política" ao arranjo de grupos em conflito é uma ideia bastante interessante. Você pode falar sobre os novos arranjos sendo desenvolvidos dentro e entre os sindicatos, movimentos sociais e o Partido Trabalhista hoje em dia, e como eles podem confluir em "um novo tipo de política radical"?

H.B. "Trabalhismo" é um termo que tem sido usado para explicar a configuração de interesses consideravelmente singular estabelecida entre o Partido Trabalhista parlamentarista e os sindicatos, na Grã-Bretanha. O Partido tomou seu nome de um comitê instaurado por líderes sindicais no começo do século passado, chamado "Comitê de Representação Trabalhista", e preocupado em afirmar a voz do trabalho (os sindicatos) no Parlamento. Ligações com intelectuais fabianos criaram uma constituição e lançaram candidatos parlamentaristas. Dessa época em diante tornou-se comum falar das "vertentes política e industrial do movimento" e esse arranjo durou até o nascimento do "New Labour" e a reconfiguração da relação entre o partido e os sindicatos. As leis antissindicais criadas pelos governos de Thatcher não foram repelidas por Tony Blair, causando uma crescente frustração. Nesta época, as minas, as siderúrgicas e todos os principais centros manufatureiros e sindicais haviam fechado as portas, o que enfraqueceu o fundamento estrutural do trabalhismo. O Partido Trabalhista mudou em consequência disso, mas os sindicatos foram mais lentos para ajustar-se a essa nova realidade e para entender que novos tipos de arranjos se faziam necessários. Enquanto isso, as desigualdades aceleraram, trazendo consigo uma mudança aguda nas atitudes, particularmente entre os mais jovens, indicando o descrédito nas elites, e uma falta de controle sobre a principais decisões que os afetavam. Tudo isso exacerbou-se com a crise de 2008 e por escândalos recor- 
rentes envolvendo os ricos e poderosos e as principais instituições do governo. Isso levou a uma variedade de diferentes formas de protesto, incluindo manifestações, ocupação de edifícios comerciais e levantes, bem como a um sentimento crescente de que os dois partidos - Trabalhista e Conservador - tinham políticas similares, de que a janela da política havia se estreitado e, por conseguinte, que a capacidade dos governos para agir em prol do "trabalho" no contexto de um capitalismo globalizado tinha sido reduzida a uma forma de gerenciamento.

J.R.R. e R.S. Tendo em mente a vida longa de uma identidade de classe ainda forte e aqueles desafios à representação política dos trabalhadores na Grã-Bretanha, como você vê as condições para que o Partido Trabalhista possa desempenhar um papel importante em um novo arranjo, especialmente sob a liderança de Jeremy Corbyn ${ }^{6}$ daqui para frente?

H.B. A eleição de Jeremy Corbyn como líder do Partido Trabalhista foi inesperada. Desde a sua eleição, a mídia britânica tem atuado da pior forma possível, retratando-o como um idiota, um excêntrico, não patriota ou um revolucionário perigoso. As dificuldades que ele enfrentou expõem de modo claro as questões levantadas anos atrás por Milliband sobre o Parliamentary Socialism e a relação que se presume existir entre membros do parlamento e membros do partido. Até recentemente, o líder do partido era escolhido pelos representantes parlamentares. Em seguida, esse processo foi alargado para incluir os sindicatos e o partido ao nível local. Inquietações sobre o poder dos sindicatos levaram, contudo, a uma mudança radical baseada no princípio de "uma pessoa, um voto". Os membros tinham um voto, os membros do sindicato tinham um voto e (de modo semelhante ao que ocorre nos EUA) apoiadores registrados do partido podiam também votar. Os parlamentares obviamente votavam e também detinham a prerrogativa de determinar o número de candidatos. Apenas candidatos nomeados apoiados por 35 parlamentares poderiam ir às urnas. Na votação final apenas I 5 parlamentares votaram em Corbyn! Outros foram persuadidos a nomeá-lo por enxergarem vantagem para seu candidato preferido ou porque sentiram que seria bom ter uma discussão mais plena. Nenhum deles previu que a nomeação levaria à eleição, muito menos a uma vitória esmagadora. Que foi o que aconteceu.

Corbyn recebeu forte apoio de todos os grupos votantes, mas emplacou mais pesadamente entre os apoiadores, milhares dos quais decidiram então ingressar no Partido. Essas pessoas eram dominadas por dois grupos. De um lado, jovens que provavelmente haviam estado envolvidos em grupos de protesto como o UK Uncut, contra a "Austeridade". De outro lado, pessoas muito mais velhas da esquerda que haviam saído da política como uma forma de protesto durante o período do New Labour (pessoas como eu). Esse desenvolvimento criou um desequilíbrio severo entre o Partido no Parlamento e o Partido 
no país, o qual terá de ser resolvido de um modo ou de outro. Para que Corbyn possa levar o Partido adiante e liderá-lo sob um programa antiausteridade/ antibélico, as estruturas de formulações de políticas do Partido - agora profundamente separadas do sistema de filiação - terão de ser realinhadas. Isso, contudo, acarretará um imenso conflito com os apoiadores de Corbyn, os quais dependem fortemente das novas mídias sociais como forma de combater o poder corporativo da imprensa e televisão nacionais, todas elas (inclusive a BBC) tendo sido incansáveis em sua disposição crítica ao novo líder.

Concedida em I4/I2/20I5 | Aprovada em 30/oI/20I6

José Ricardo Ramalho é Professor Titular do Departamento de Sociologia e do Programa de Pós-Graduação em Sociologia e Antropologia (PPGSA) da Universidade Federal do Rio de Janeiro (UFRJ). Fez doutorado e mestrado em Ciências Sociais (Ciência Política) na Universidade de São Paulo, e pós-doutorados na Universidade de Londres e na Universidade de Manchester, no Reino Unido. Sua atuação acadêmica está mais voltada para a área da Sociologia do Trabalho e seus principais temas de pesquisa são: relações de trabalho na indústria; sindicato e sindicalismo; reestruturação produtiva e distritos industriais; trabalho, emprego e desenvolvimento econômico regional e local; e identidade operária.

Rodrigo Santos é Professor Adjunto do Departamento de Sociologia e do Programa de Pós-Graduação em Sociologia e Antropologia (PPGSA) da Universidade Federal do Rio de Janeiro (UFRJ). Suas pesquisas nas áreas de Sociologia Econômica, do Desenvolvimento e do Trabalho voltam-se para temas como: mudança social, globalização, desenvolvimento, estratégia corporativa, mineração, siderurgia e indústria automobilística. Coordena o grupo de pesquisa Política, Economia, Mineração, Ambiente e Sociedade (PoEMAS), é membro do Comitê Nacional em Defesa dos Territórios frente à Mineração (CNDTM) e assessora o Movimento Nacional pela Soberania Popular frente à Mineração (MAM). 


\section{NOTAS}

I O estalecimento do convênio acadêmico CAPES/British Council, The reorganization of work and labour in contemporary Brazil and Britain (I994-I997) demarca o início de um processo colaborativo que aproximaria os debates das tradições brasileira e britânica da Sociologia do Trabalho, desenvolvendo, através de encontros e missões científicas, trabalhos de pesquisa e publicações conjuntos, além do intercâmbio de estudantes e pesquisadores de ambos os países.

2 Aneurin Bevan (I897-I960) foi Ministro da Saúde entre I945 e I95I, período no qual foi estabelecido o Serviço Nacional de Saúde (National Health Service - NHS), e Ministro do Trabalho (I95I), tendo liderado, após sua renúncia ao cargo, a ala esquerda do Partido Trabalhista, que ficou conhecida como os Bevanites.

3 Edward Webster é Professor Emérito no Society, Work and Development Institute (SWOP) da Universidade de Witwatersrand e diretor do Chris Hani Institute, no Congress of South African Trade Unions (COSATU).

4 Um sistema clandestino de cópia e distribuição de literatura censurada na antiga União Soviética.

5 Kenneth Sidney Coates (I930-20I0) foi um trabalhador mineiro, sociólogo e político britânico, com longa militância em favor do controle operário.

6 Jeremy Corbyn tornou-se o líder do Partido Trabalhista em I 2 de setembro de 2015 . 
Palavras-chave

Marx;

Sociologia Crítica; Sociologia do Trabalho;

Trabalhadores; Sindicatos

Keywords

Marx;

Critical Sociology;

Sociology of Work;

Workers;

Trade unions.

\section{HUW BEYNON: MARXISMO E SOCIOLOGIA}

\section{Resumo}

A entrevista com o sociólogo britânico Huw Beynon, autor de Trabalhando para a Ford, entrelaça as dinâmicas de trajetória intelectual, desenvolvimento institucional da sociologia (do trabalho, em particular), da política britânica e da tradição marxista. O autor reflete sobre uma vasta experiência na construção e difusão de uma sociologia crítica, centrada no engajamento com seu objeto e público extraacadêmico. Destacam-se aqui as experiências em educação de adultos e de extensão com trabalhadores, as primeiras expressões da globalização e neoliberalismo como "movimento de fechamento" de fábricas - assim como as reações acadêmicas e sindicais ao processo -, além de respostas político-culturais recentes acerca da preservação de uma identidade operária enraizada e da reconstrução do Partido Trabalhista em torno da adesão da juventude. A entrevista com Huw Beynon sintetiza os elementos de uma obra que é parte inseparável das transformações no mundo do trabalho nos últimos cinquenta anos, assim como se apresenta como inestimável para sua compreensão sociológica.

\section{HUW BEYNON: MARXISM AND SOCIOLOGY}

\section{Abstract}

In this interview with British sociologist Huw Beynon, author of Working for Ford, the dynamics of his intellectual trajectory, the institutional development of sociology (of labor, specially), British politics and Marxist tradition are entwined. The author reflects on an extensive involvement in setting up and advancing critical sociology, focused on engaging with its object and extra academic audience. We highlight his practice in adult education and "extra mural" activities with workers, the first expressions of globalization and neoliberalism as a "closure movement" of factories - and the academic and trade union reactions - as well as recent political and cultural responses towards the preservation of labor identity and the reconstruction of the Labour Party around youth membership. The interview with Huw Beynon summarizes a body of work that is as much inseparable of the changes in the world of labor over the past fifty years as is priceless to its sociological understanding. 